\title{
Technical modifications for the Wagner SL hip arthroplasty. Short oblique osteotomy of the proximal $1 / 3$ of the femur
}

\author{
Ph. Vichard, E. Gagneux and P. Garbuio
}

Service de Chirurgie Orthopédique, Traumatologique et Plastique (Pr Vichard), CHU, Hôpital Jean-Minjoz, F 25030 Besançon cedex

Summary: 58 Wagner prostheses were implanted between 1989 and 1996. This was done through a simplified technique without trochanteric osteotomy or grafting. The Wagner transfemoral approach was only used once. The other operations were done through the Moore approach. Classical windows were not used since we feel they give a poor view and predispose to later fractures. We distinguished between the simple cases using the intra-medullary route with image intensifier control, and the difficult cases where the short oblique subtrochanteric osteotomy was used. This manouvre was the simplest way of removing the cement and the prosthesis and of inserting a Wagner prosthesis of $265 \mathrm{~mm}$ or longer which also requires a diaphyseal osteotomy to prevent cortical splitting. The Wagner transfemoral route is only needed for removal of uncemented prostheses. Infection is a good indication for this technique where a one stage revision is planned. This technique, like the pure intra-medullary route is derived from the principles of closed intra-medullary nailing.

Key words: Hip arthroplasty - Wagner prosthesis

Code Méary: 4233.2

Correspondence to: $\mathrm{Ph}$. Vichard
Most orthopaedic surgeons are familiar with the Wagner SL prosthesis (Figs 1 and 7), which he uses for some inter-trochanteric fractures and above all for revision of loose hip prostheses with marked loss of bone stock $[1,7]$.

Nowadays, we only use the most recent version of this prosthesis and for current cases we rapidly abandoned the transfemoral route which was devised for the most difficult cases.
Indeed, the bloody and ragged femoral shell with or without a transverse osteotomy worried us from the beginning. Similarly, we have for some time given up classical or even anterior windows which give a poor view of the cement and the prosthesis to be removed and may be a source of later fracture. On the other hand, the design itself of the and generation Wagner prosthesis, with a wide range of lengths
Fig. 1 a, b

Wagner prosthesis. a) left: original version, b) right: most recent version. In the original model, the conical part was always the same length whatever the size of the prosthesis. The new prosthesis has 8 longitudinal ridges and is conical over its whole length 


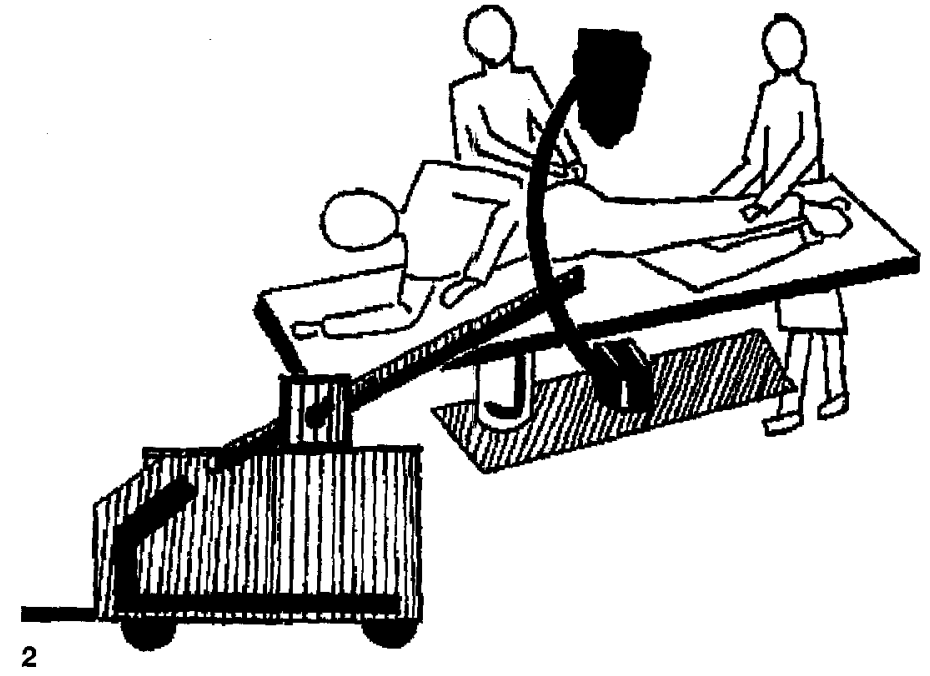

Fig. 2

Positioning the image intensifier

Fig. 3

The bit drilling the distal plug while remaing in the long axis of the femur

Fig. 4

Revising the canal with the hook gouge
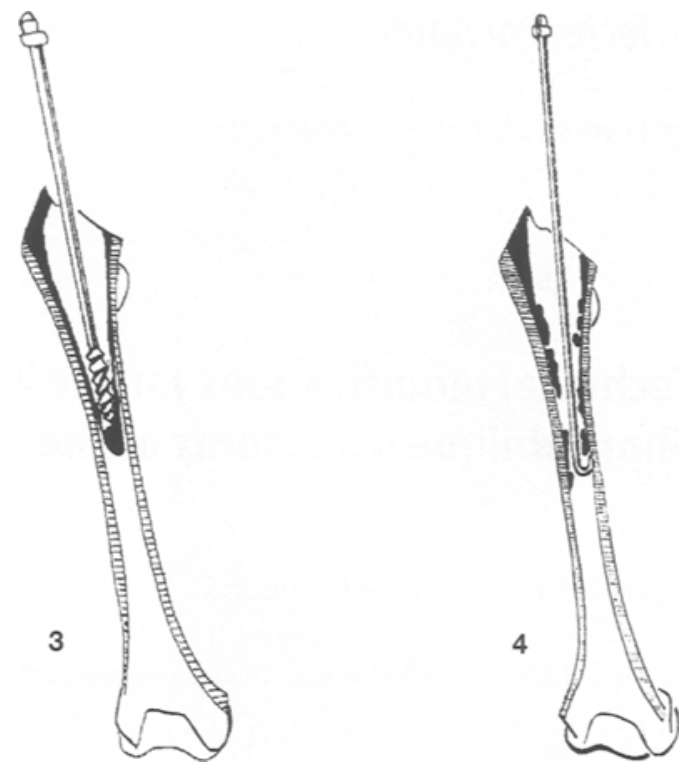

and diameters, the fixation obtained by the 8 ridges around which osteo-integration occurs [4], and its universal nature (right and left) has led us to use it since 1989 for the indications envisaged by Wagner and then in other situations. We have studied 58 protheses with a followup from 6 months to 7 years.

\section{Personal technique}

The Moore approach was used which often required revision of scars from previous procedures. With aseptic femoral loosening the prosthesis was usually easy to remove. Setting aside the possible work on the acetabulum, the femoral stage then consists of removal of the most proximal cement with classical instruments with suction irrigation and good illumination down the axis of the femoral canal (eg. cold light source). The adherence of the cement to the bone is very variable. Rarely, most of the cement will come out with the prosthesis.

\section{Simple cases}

Our technique barely differs from that of most surgeons. We use the intra- medullary route exclusively [5]. We are loath to use aiming devices which require extensive exposure of the femur. Long experience with closed nailing leads us to prefer the image intensifier. The radiation is measured and, taking certain precautions (distance of the operator, direction of the beam, operator protection) its use is legitimate [3]. It remains in one position. The beam is vertical (Fig. 2). One first obtains a lateral view and then the AP by turning the femur into $90 \mathrm{deg}$ internal rotation. The image intensifier allows drilling of the cement plug keeping the drill bit in the line of the femur (Fig. 3). The hole is then enlarged to pass a hook for final removal of the plug. Clearing the walls of the intra-medullary cavity is done with gouges and curette (Fig. 4) with intermittent checks with the image intensifier (2nd use of the latter).

Once the cement has been removed, the Wagner reamers are used to determine the size of prosthesis to be used. We restricted all cases to 180 or $225 \mathrm{~mm}$ prostheses. Using a Wagner prosthesis did not have any major disadvantage compared to normal sized cemented or uncemented prostheses. The third and last use of the image intensifier was to monitor the insertion of the new prosthesis with the aim of avoiding jamming on residual plaques of cement.

The indications were much more specific in the difficult cases.

The difficult cases were

a) Intra-medullary breakage of the prosthetic stem (Fig. 5).

b) Very long prosthesis to be exchanged.

c) Very thick, or long distal extension of the cement mantle.

d) The formidable problem of removing uncemented prostheses for breakage or, more often infection, but still fixed to bone. In these, the rarest cases, we have no other solution than Wagner's transfemoral approach. However, in the case of an infected Wagner prosthesis still fixed to bone, we were able to extract it by passing Kirschner wires down the grooves between the ridges of the prosthesis.

e) Infections requiring complete and meticulous removal of cement as well as the prosthesis.

For cases $a, b, c$ and $e$, in addition to windows we rejected the idea of prolonged, laborious and haemorragic intra-medullary extractions which are 

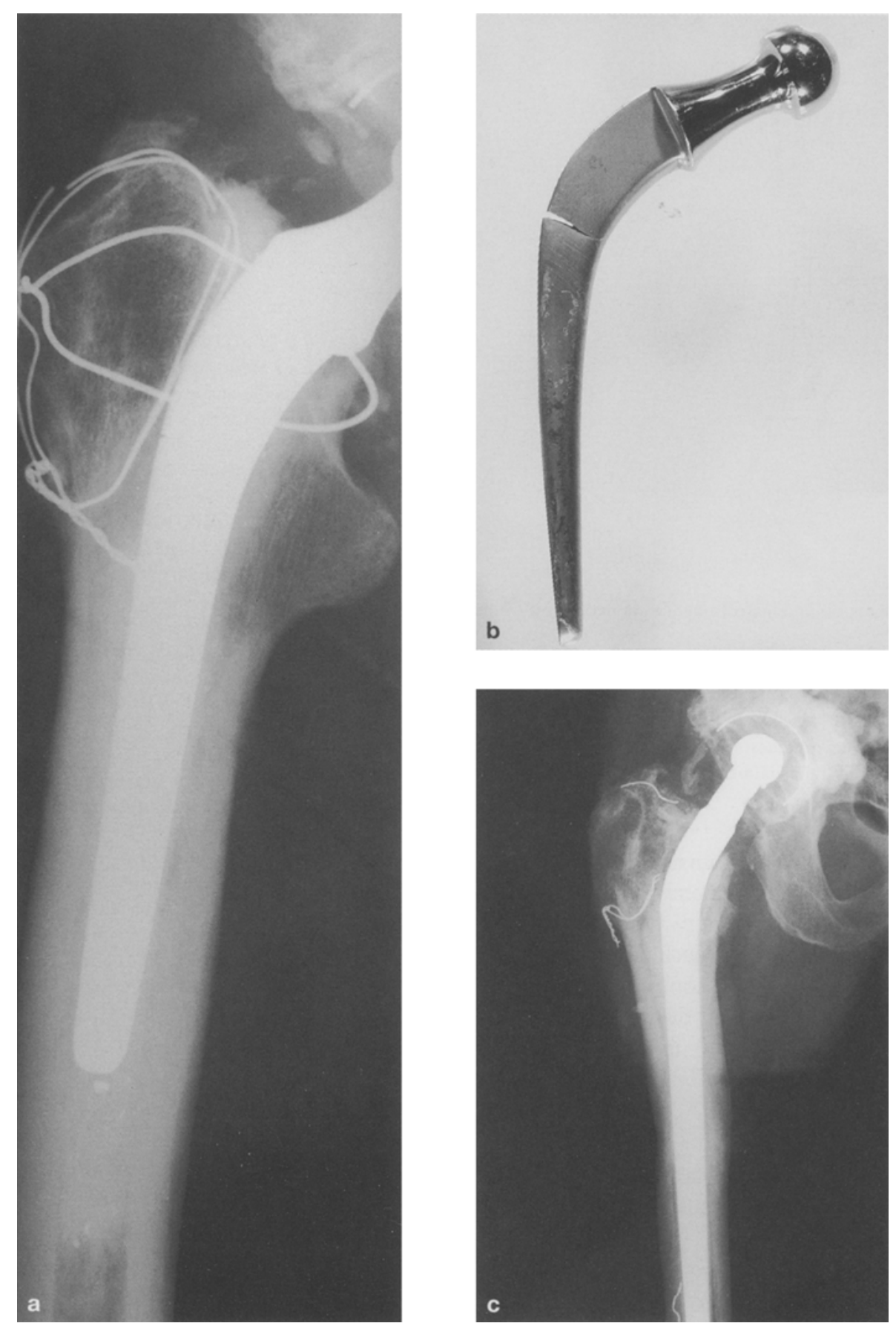

Fig. 5a, b, c

Prosthetic stem broken in the medullary canal, a) pre- operative appearance, b) the removed prosthesis, c) Wagner prosthesis in place with consolidation of the osteotomy

a source of excessive irradiation, false passages and even fracture.

We inceasingly resorted to the short oblique osteotomy of the proximal $1 / 3$ of the femur (Fig. 7 ). Its short obliquity is to avoid post-operative rotation. The site of the osteotomy is determined by pre-operative templating as a function of any prosthetic breakage, the level of the femoral isthmus and the extent of the cement. The osteotomy is done with an oscillating saw with minimal periosteal stripping. It is preceeded by placing Hohman retractors, one anteriorly under the quadriceps and one posteriorly on the linea aspera. One can then grasp each of the fragments with a bone holding clamp. Rapid open removal of proximal and distal cement cement, with osteotomes and reamers, can then be done without risk as well as removal of a broken stem which can be pushed proximally. This osteotomy also permits correction of any unfavourable anatomical or pathological deformity of the femur. The direction of the osteotomy is orientated as a function of this deformity. Fixation of the osteotomy is done with a 265 or $305 \mathrm{~mm}$ Wagner prosthesis. It should be noted that all Wagner prostheses of $265 \mathrm{~mm}$ or longer require an osteotomy to prevent cortical splitting which most ofter occurs anteriorly. A wire suture is often needed to prevent the proximal fragment slipping because of its large diameter (due to its anatomy, the large cavity created by cement removal and the granuloma). This suture is from side to side (Fig. 7) or to the greater trochanter or even the gluteus medius. However this technique of osteotomy can only be used with a one stage revision in infections. We have had no complications with 8 sub-trochanteric osteotomies (out of 58 Wagner arthroplasties).

Other features of the technique used

There was never any requirement for trochanteric osteotomy or bone graft.

\section{Post-operative care}

The suction drains were removed between the third and fourth days. The lower limb was held in abduction for three days with a Charnley wedge. Traction suspension in abduction for 21 to 45 days was used where there were worries about the trochanteric fragment migrating proximally, bearing in mind the tenuous hold of the wire suture in the bone and the frequent deterioration of the proximal fragment. In those cases where the distal diaphysis is fragile, porotic or even pellucid, and the risk of impaction and even fracture is high, offloading of variable duration is required depending on the pathology. 

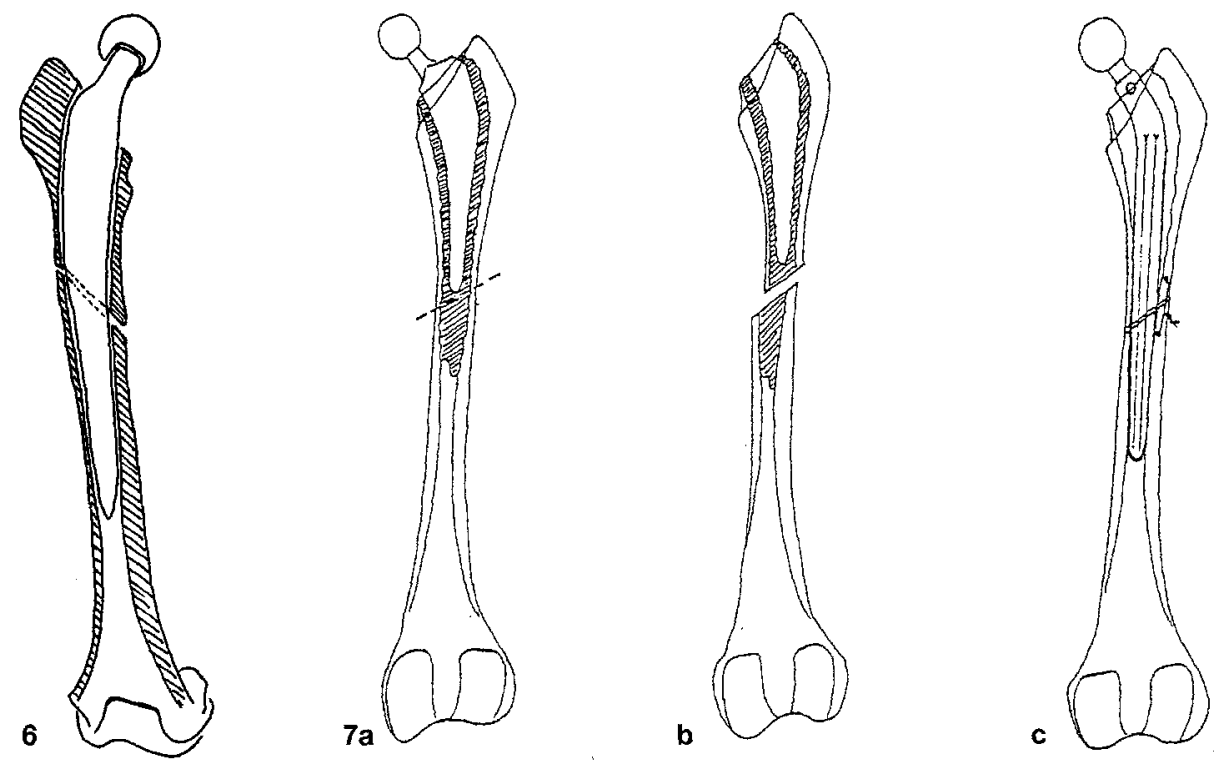

Fig. 6

Drawing of a very long prosthesis to be removed. A short oblique osteotomy allows extraction of the cement

Fig. $7 a, b, c$

The short oblique osteotomy of the proximal third of the femur. a) Massive cement mantle or broken prosthesis. b) Removal of the prosthesis: short oblique osteotomy above the isthmus, complete removal of cement via the osteotomy. c) Insertion of the Wagner prosthesis which grips in the distal fragment. Note the wire suture to pevent proximal migration of the proximal fragment

\section{Conclusion}

The short oblique osteotomy of the proximal third has been extremely useful in simplifying the complete removal of cement. We encountered no specific complications of this technique.
However it is unsuitable for the removal of long uncemented prostheses, such as Wagner's, in which case we use the transfemoral approach described by him. Infection is also a contraindication where revision is being done in two stages. Femoral osteotomy in a ruined femur is clearly preferable to intramedullary removal which, come what may, produces frequent fractures which are difficult to repair due to their type, or to the use of devitalising plates on the femur. Respect for the soft tissues is the basis of this technique which has been inspired by the principles of closed nailing.

\section{References}

1. Hartmann D (1995) La prothèse fémorale de reprise SL de Heinz Wagner. A propos de 42 cas. Thesis, Besançon

2. Lamy H (1993) Reprises des descellements fémoraux de prothèses totales de hanche par prothèses non cimentées de Lord et de Wagner. Thesis, Strasbourg

3. Sanders R, Kenneth JK, Thomas DP (1993) Exposure of the orthopedic surgeon to radiation. J Bone Joint Surg [Am] 75: 326-330

4. Schenk RK, Wehrli U (1989) Zur Reaktion des Knochens auf eine Zementfreie slFemur-revisionsprothese. Histologische Befunde an einem fänfeinhalb Monate postoperationem gewonnenen Autopsiepräparat. Orthopäde 18: 454-462

5. Vichard Ph, Brientini JM, Elias BE (1992) L'extraction du ciment périprothétique fémoral. Intérêt de la voie endomédullaire pure. Rev Chir Orthop 78 [Suppl 1]: 212

6. Vives P (1989) Descellement aseptique des prothèses totales de hanche repris par prothèse cimentée. Symposium. Directeur P. Vives. SOFCOT, $38^{\mathrm{e}}$ réunion annuelle, novembre 1968. Rev Chir Orthop 75 [Suppl 1]: 23-60

7. Wagner $\mathrm{H}(1989)$ Prothèse de révision de l'articulation coxo-fémorale. Orthopäde 18: 438-453

Received July 8, 1998 / Accepted in final form Septernber 15,1998

\section{Modifications techniques apportées à l'arthroplastie de hanche selon Heinz Wagner : l'ostéotomie transverso-oblique du $1 / 3$ proximal du fémur}

Résumé : 58 prothèses selon H. Wagner ont été posées entre 1989 et 1996. Elles l'ont été selon une technique simplifiée qui a exclu toute trochantérotomie, toute greffe. Une seule voie transfémorale de Wagner est utilisée. Toutes les autres interventions ont emprunté la voie de Moore. Il n'y a eu aucune fenestration classique qui nous semble donner un mauvais jour et prédisposer à la fracture ultérieure. Nous distinguons les cas simples où la voie endo-canalaire pure, grâce à l'amplificateur de brillance, est utilisée et les cas complexes (cimentage étendu, rupture de prothèse) où l'ostéotomie transverse oblique sous-trochantérienne est l'artifice le plus simple pour enlever le ciment et la prothèse et mettre en place une prothèse de Wagner dont la longueur, supérieure ou égale à $265 \mathrm{~mm}$, impose aussi l'ostéotomie diaphysaire pour éviter l'effraction corticale. Seule l'extraction de prothèses non cimentées impose la voie transfémorale de Wagner. Quant aux infections, elles sont une bonne indication de cette ostéotomie dans la mesure où le chirurgien envisage une reprise en un temps. Cette technique comme la voie endocanalaire pure, s'inspire des principes de l'enclouage centromédullaire à foyer fermé.

Mots clés : Arthroplastie de hanche - Prothèse de Wagner 